\title{
Selection of diving strategy by Antarctic fur seals depends on where and when foraging takes place
}

\author{
Simon D. Goldsworthy ${ }^{1, *}$, Brad Page ${ }^{1}$, Andrew Welling ${ }^{2}$, Magaly Chambellant ${ }^{3,5}$, \\ Corey J. A. Bradshaw ${ }^{1,4}$ \\ ${ }^{1}$ South Australian Research and Development Institute-Aquatic Sciences Centre, 2 Hamra Avenue, West Beach, \\ South Australia 5024, Australia \\ ${ }^{2} 434$ Van Morey Road, Margate, Tasmania 7054, Australia \\ ${ }^{3}$ Centre d'Études Biologiques de Chizé-Centre National de Recherche Scientifique, 79360 Beauvoir-sur-Niort, France \\ ${ }^{4}$ The Environment Institute and School of Earth and Environmental Sciences, University of Adelaide, Adelaide, \\ South Australia 5005, Australia \\ ${ }^{5}$ Present address: Fisheries and Oceans Canada, 501 University Crescent, Winnipeg, Manitoba R3T 2N6, Canada
}

\begin{abstract}
We investigated the spatial and temporal distribution of foraging effort by lactating Antarctic fur seals Arctocephalus gazella at Heard Island using satellite telemetry and time-depth recorders. Two principal diving types were identified: 'deep' dives averaging $48.6 \mathrm{~m}$, and 'shallow' dives averaging $8.6 \mathrm{~m}$. Discriminant function analyses were used to assign dives based on their depth and duration. Generalised linear mixed-effects models of night dives ( $>80 \%$ of all dives) indicated both spatial and temporal effects on the distribution of deep and shallow dives. Deep dives were more common in the deeper shelf waters of the Kerguelen Plateau, and these dives predominantly occurred after sunset and before sunrise. In contrast, shallow dives were more common in slope waters on the southeastern margin of the Kerguelen Plateau in the hours either side of local midnight. We suggest that these 2 distinct diving types reflect the targeting of channichthyid (deep dives) and myctophid (shallow dives) fish, and are indicative of spatial and temporal differences in the availability of these 2 important prey groups. We also identified 3 distinct behavioural dive groups (based on multidimensional scaling of 19 diving and foraging trip parameters) that also differed in their spatial distribution and in their relative importance of deep and shallow dives. The present study provides some of the first evidence that diving strategies are not only influenced by where foraging takes pace, but also when.
\end{abstract}

KEY WORDS: Diving $\cdot$ Arctocephalus gazelle $\cdot$ Spatial foraging $\cdot$ Southern Ocean $\cdot$ Temporal variability

\section{INTRODUCTION}

The high spatial heterogeneity in marine productivity and prey availability provides extensive challenges for large marine predators that are required to process information from multiple spatial scales to find prey. For land-breeding marine predators such as fur seals and sea lions, lactation places even greater constraints on foraging behaviour. Females alternate between foraging at sea and nursing pups ashore, during which time the distribution and availability of prey can change. In addition, compared to non-breeding animals, they are spatially constrained in their foraging, having to return regularly to the colony to nurse their pup. They are also temporally constrained by the fasting abilities and growth requirements of their offspring. As such, fur seals and sea lions typically breed close to regions where the availability of prey is predictable (Gentry et al. 1986a).

To facilitate the exploitation of prey near their colonies, lactating fur seals have adopted a strategy of stereotypy in the distance and direction of successive trips from the colony to foraging areas. Many studies have reported this pattern, which is thought to result from a combination of geographic (coastline orientation) and oceanographic (bathymetry and proximity to 
fronts/upwellings) conditions; colony-level memory of specific foraging areas; and individual memory of previous foraging success (Bonadonna et al. 2001, Boyd et al. 2002, Beauplet et al. 2004, Bradshaw et al. 2004, Robson et al. 2004, Staniland et al. 2004, Page et al. 2006, Baylis et al. 2008, Biuw et al. 2009). Studies on Antarctic fur seals Arctocephalus gazella suggest that foraging routes remain similar between successive trips, but prey availability along the way determines whether females use near (shelf), or distant (oceanic) habitats (Goebel et al. 2000, Staniland \& Boyd 2003, Staniland et al. 2004, Staniland et al. 2007). Using prior experience and responding rapidly to changes in prey availability enables pelagic foragers to track highly mobile prey resources. As such, pelagic foragers allocate time and energy into exploiting many different prey species during each foraging trip (Boyd 1996, Weimerskirch et al. 1997, Le Boeuf et al. 2000, BenoitBird \& Au 2003, Robinson et al. 2007). This is especially so if pelagic foragers transit between habitats during a single day (Macdonald \& Rushton 2003), and where diel movements of prey might require the predator to make adjustments to the foraging depth window.

Horizontal movements (distance and direction travelled) of predators provide information on the distribution of prey over broad spatial scales (Hooker \& Baird 2001), but it is diving behaviour that provides a measure of effort and information about where predators encounter their prey. This information can then be used to draw inferences about the vertical distribution of prey (Austin et al. 2006). Staniland \& Boyd (2003) showed that the distances travelled to foraging areas varied markedly depending on whether adult female fur seals targeted shelf, oceanic, or far oceanic regions. Within each region, diving behaviour varied considerably in terms of the frequency and depth of night and day dives. Shelf foragers continued diving throughout the day, but oceanic foragers dived predominantly at night. This could indicate smaller diel vertical migrations of krill in shelf waters or that shelf and oceanic foragers target different prey species (Staniland \& Boyd 2003). A recent study supporting the latter hypothesis indicates that diet varies between shelf and oceanic habitats (Staniland et al. 2007).

Research on other fur seal species has quantified changes in diving behaviour associated with changes in prey species and region (Beauplet et al. 2004, Page et al. 2005). In northern fur seals Callorhinus ursinus, both diving behaviour (Gentry et al. 1986b, Goebel et al. 1991, Sterling \& Ream 2004) and diet (Sinclair et al. 1994, Antonelis et al. 1997, Zeppelin \& Ream 2006) vary in relation to the type of foraging habitats and bathymetric structure adjacent to breeding colonies. Throughout lactation, sub-Antarctic fur seals Arctocephalus tropicalis at Amsterdam Island demonstrate a change in diet associated with a north-south shift in the location of a major frontal zone (the subtropical front) (Beauplet et al. 2004).

Lea et al. (2002a) described 4 distinct dive behaviour groups in Antarctic fur seals at Iles Kerguelen based on a range of diving parameters: (1) deep, (2) shallow active, (3) shallow, and (4) daytime divers. Deep and shallow active seals spent similar time at sea diving (24 and $22 \%$, respectively); the mean depth of deep diving seals was greater than for shallow active seals (63 and $41 \mathrm{~m}$, respectively). Shallow diving seals had both lower time spent diving (14.5\%) and similar mean dive depth (36 m) to shallow active divers (Lea et al. 2002a). Daytime divers were distinct from the other behavioural dive groups, with $41 \%$ of dives occurring during the day (Lea et al. 2002a). The breadth of diving strategies observed reflected differences in prey availability, foraging experience, and metabolic requirements between seals (Lea et al. 2002a). However, differences in dive behaviour might also reflect the targeting of different prey by a particular group. The high variance in the depths and times of diving by Antarctic fur seals suggests that both spatial and temporal factors affecting prey availability determine the diving behaviour observed. Here we examine: (1) the spatial and temporal variation in diving strategies of lactating Antarctic fur seals at Heard Island, (2) how these might relate to the spatial and temporal distribution of their prey and how diving behaviour compares with that of the other main population of Antarctic fur seals on the Kerguelen Plateau at Iles Kerguelen.

\section{MATERIALS AND METHODS}

Data collection. Argos-linked satellite platform transmitter terminals (PTTs, $110 \times 42 \times 14 \mathrm{~mm}$, KiwiSat 101, Sirtrack) and time-depth recorders (TDRs, MK-7 TDRs Wildlife Computers) were attached to lactating Antarctic fur seals between December 2000 and February 2001 at Spit Bay, Heard Island $\left(53.108^{\circ} \mathrm{S}\right.$, $73.738^{\circ} \mathrm{E}$ ). A total of 32 females were fitted with TDRs, of which 22 were simultaneously fitted with PTTs. Females were monitored over a single foraging trip (range 2.7 to $10.3 \mathrm{~d}$ ) to maximise the number individuals sampled over the short field season. PTTs and TDRs were glued to the fur on the dorsal midline using a flexible-setting epoxy (Araldite 2017, Vantico). Females were captured by hoop net in the colony and physically restrained for up to 20 min during equipment attachment. The depth resolution of the TDRs was $1 \mathrm{~m}$, and sampling was set to $5 \mathrm{~s}$ intervals. Data were extracted from TDRs using software supplied by the manufacturer and processed for zero-offset correction (manual correction, surface error set to $\pm 1 \mathrm{~m}$ ) 
using Instrument Helper (v. 1.0.0.5, Wildlife Computers). Corrected files were analysed using the dive analysis feature of the same software. Minimum dive depth was set to $2.5 \mathrm{~m}$.

Satellite location data were obtained through Service Argos (Toulouse, France). The location-class of ' $\mathrm{Z}$ ' positions were omitted due to the magnitude of their error (Sterling \& Ream 2004). The R statistical package (R Development Core Team 2009) and the timeTrack library (v. 1.1-5, M. D. Sumner, University of Tasmania, Hobart) were used to apply the speed filter described by McConnell et al. (1992), based on a maximum possible horizontal speed of $7.2 \mathrm{~km} \mathrm{~h}^{-1}$ to the remaining location data (B, A, 0, 1, 2, 3 class positions). Given the potential error associated with B, A, and 0 locations (Boyd et al. 1998, Robson et al. 2004), this filtering procedure removed unreliable positions that exceeded the maximum possible speed required to reach them from the previous accepted location.

Discrimination of dive types. Through analysis of dive records, 2 distinct modes of diving (deep and shallow) were apparent, and these typically occurred in discrete bouts (Fig. 1). Shallow dives occurred in near-surface waters and were of shorter duration than deep dives. To aid objective classification of these dive types, samples of 100 shallow and 100 deep dives where taken from 14 individual dive records where both dive types occurred (one exception where 50 nearsurface and 50 deep dives were sampled), giving a total of 1350 shallow and deep dives in the sample (2700 in total). Sample dives were taken from bouts of shallow and deep diving based on visual classification as shown in Fig. 1. Each dive record included maximum depth $(\mathrm{m})$ and duration (s), and was classified according to nominal dive type. A backwards stepwise discriminant function analysis (DFA) $(\alpha$ to enter and remove $=0.150)$ (SYSTAT v. 10) provided the reliability of discriminating between dive types, and a discriminant equation. The DFA indicated that dive types differed based on depth and duration (Wilks' lambda $=0.239$, df $=2$, $\mathrm{p}<0.001$ ), and correctly assigned $97 \%$ of dives (jack-knife classification matrix:

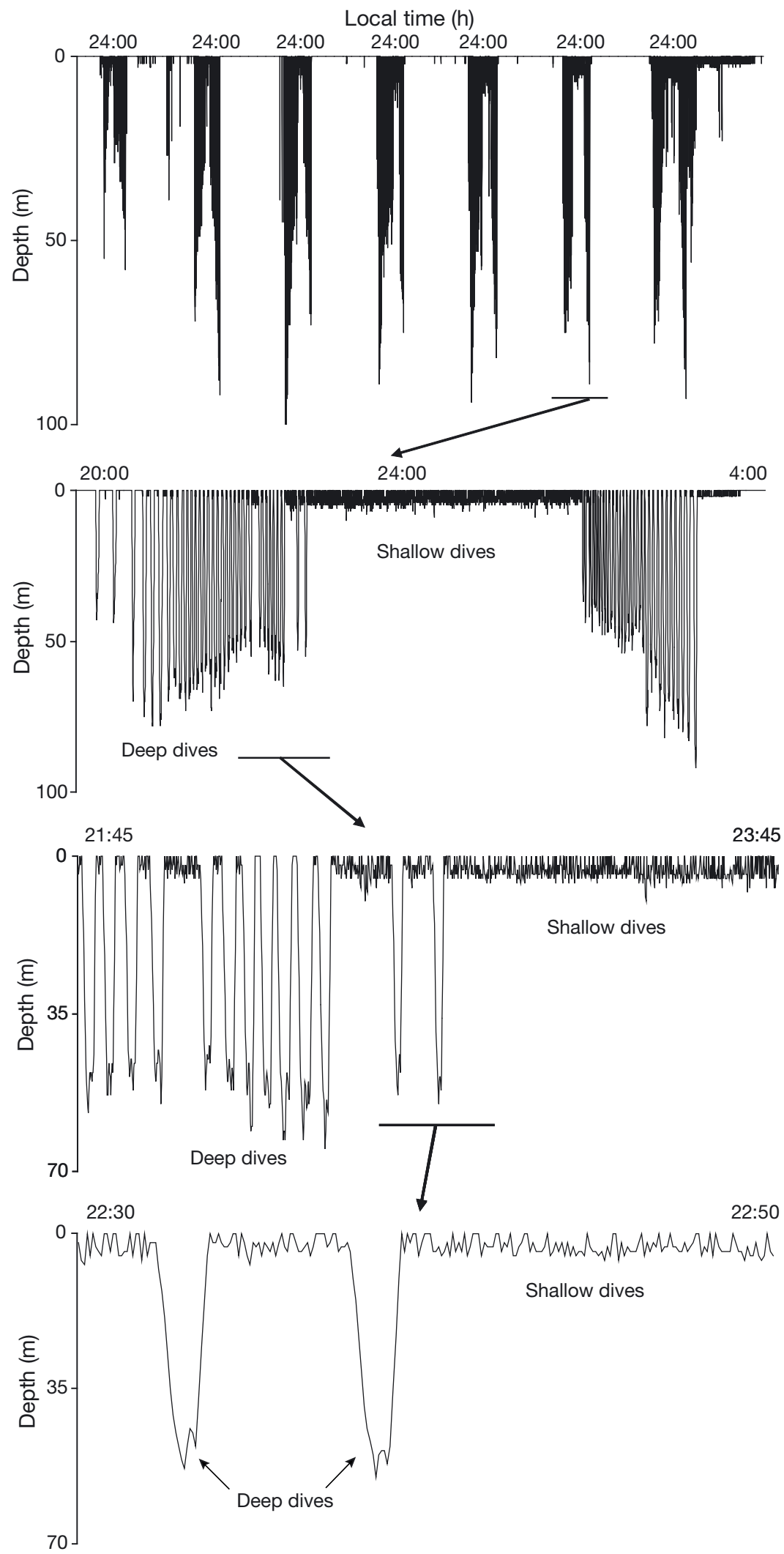

Fig. 1. Arctocepahlus gazella. Example of a diving record from one lactating Antarctic fur seal indicating deep and shallow dives 
$99 \%$ correctly assigned to shallow group, 94\% correctly assigned to deep group), based on the following discriminant equation: shallow (-ve)/deep $(+v e)=$ $-2.713+0.021_{\text {depth }}+0.026_{\text {duration. }}$. A DFA that included depth only correctly assigned $94 \%$ of dives $(100 \%$ shallow, $89 \%$ deep; discriminant equation $(-\mathrm{ve}) /$ deep $\left.(+\mathrm{ve})=-1.87+0.059_{\text {depth }}\right)$ (i.e. dives $<32 \mathrm{~m}$ were classed as shallow).

Night and day periods. Sunrise and sunset times were calculated for the Heard Island region using the Sol Solar Calculator (v. 1.0.0.7, ONick Hubbard). Sunrise and sunset times were used to determine if individual dives occurred during night or day periods. During the study period, night duration ranged from 7.53 to $9.28 \mathrm{~h}$ (mean sunrise and sunset time 04:05 $\mathrm{h}$ and 20:14 h local time, respectively, UTC $+5 \mathrm{~h}$ ).

Diving parameters. A total of 19 diving and foraging trip parameters were derived from dive records, most based upon those used by Lea et al. (2002a), but also the depth and frequency of deep and shallow dives. These parameters were: (1) dive frequency (no. of dives $\mathrm{h}^{-1}$ ); (2) night dive frequency (no. of dives $\mathrm{h}^{-1}$ of night); (3) mean dive depth (m); (4) mean depth (m) of deep dives; (5) mean depth (m) of shallow dives; (6) mean dive duration $(s)$; (7) proportion of time submerged (sum dive durations of dives $\geq 2.5 \mathrm{~m}$ divided by duration of the foraging trip); (8) foraging trip duration (d); (9) proportion of dives at night (no. of dives at night divided by total no. of dives); (10) proportion of night time spent submerged; (11) vertical depth travelled $\mathrm{h}^{-1}$ night; (12) proportion of total vertical depth travelled at night; (13) vertical depth travelled $\mathrm{d}^{-1}$; (14) proportion of night spent undertaking shallow dives; (15) proportion of dives in bouts (see below); (16) mean number of dives per bout; (17) proportion of total dive duration spent on deep dives; (18) maximum distance reached $(\mathrm{km})$ from the colony; and (19) the bearing (heading) to the maximum distance.

The methods used by Harcourt et al. (2001) and Lea et al. (2002a) to calculate the duration of dive bouts were not suitable for the dive records we analysed because changes in surface intervals (especially when changing from shallow to deep dives) often resulted in incorrect bout termination. We found that dive bouts could be unambiguously determined if the post-dive surface intervals were less than $5 \mathrm{~min}$. Subsequent dives were included as long as the post-dive surface interval did not exceed $5 \mathrm{~min}$. To examine whether seals could be placed into behavioural dive groups based on the dive parameters detailed above, we followed a similar multidimensional scaling approach used by Lea et al. (2002a) to identify similar groups of seals, but instead applied a Bray-Curtis similarity matrix and hierarchical clustering analysis. The significance of cluster groups was tested by similarity profile
(SIMPROF) analysis in Primer 6 (Clarke \& Warwick 2005). The accuracy of assigning seals to particular dive behaviour groups based on the clustering analyses was tested using a backwards discriminant function analysis (DFA), and a jackknife analysis was then used to verify the accuracy of the DFA (DFA, SYSTAT v. 10).

Spatial and temporal distribution of dives. To determine the spatial distribution of diving effort around Heard Island, we used the timeTrack library (R language) to interpolate the location of each dive by calculating the mean travel speed based upon the time and distance between successive filtered Argos locations. This enabled spatial analyses of the distribution of diving effort for the behavioural dive groups and individual dive types. The interpolated positions of dives were overlayed with a bathymetric layer to estimate the water depth $(\mathrm{m})$ and seafloor gradient (change in depth in $\mathrm{m}$ for each horizontal kilometer) where each dive occurred. The great-circle distance between the colony and each dive $(\mathrm{km})$ was calculated as well as the local time of each dive.

The spatial distribution of dive types and behavioural dive groups was also visualised (but not analysed) by plotting the proportion of individual dives that occurred within $10 \times 10 \mathrm{~km}$ grid cells summed and assigned to central nodes. To ensure that different deployment durations did not bias comparisons, time spent diving in each cell was converted to the proportion of the total time spent diving by each seal. Proportional values of time spent in area (by dive behaviour group and type) were plotted using the triangulation with smoothing function in VerticalMapper ${ }^{\circledR}$ (v. 2.5) and MapInfo ${ }^{\circledR}$ (v. 8.0, MapInfo Corporation).

To determine the relationships between deep versus shallow diving with respect to the attributes of the foraging area and time of day, we fitted a series of generalised linear mixed-effect models (GLMM) to the data using the lmer function in the R package (R Development Core Team 2009). To control for temporal autocorrelation between dives and to test the hypothesis that diving changes as a function of light availability, we calculated the time of local midnight and then divided the location/time-specific sunset to sunrise period into 4 equal bins (Bins 1 to 4), with Bin 1 centred on local midnight and Bin 4 set as the periods just after sunset and before sunrise. Bin 5 referred to the periods prior to sunset and just after sunrise, and Bin 6 included the dives occurring during the remainder of the day. For each bin, the proportion of deep dives per day per female was calculated and used as the response variable. Average bathymetric depth and gradient were calculated for each bin. All fixed effects were median-centred $\left(x_{i}^{\prime}=x_{i}-\widetilde{X}\right)$ so that estimated term coefficients could be interpreted as the effect of a fixed 
term on the proportion of deep dives at the mean value of all other fixed effects.

For each GLMM, we coded the response as 0 for hour bins with no deep dives, and all others as 1 if deep diving occurred. The resultant binomial response (with a logit link function) was weighted by the proportion of deep dives per bin to account for variable diving behaviour. A weighted binomial model was chosen to avoid problems with variance inflation at the extremes of proportional distributions. Dives can represent specific, individual foraging strategies and might not be statistically independent, so it was still necessary to decompose the variance across individuals by coding the random-effects error structure of the GLMM as an individual effect (Blackburn \& Duncan 2001). The amount of variance in the proportion of deep dives per hour bin response variable that was captured by each model (see below) was assessed as the percent deviance explained (\%DE) expressed relative to the deviance of a null model with no fixed effects but retaining the hierarchical random effect (Brook et al. 2006). Two different analyses were carried out: (1) all dives (i.e. all bins), and (2) only night bins (Bins 1 to 4 ); to examine the finer-scale structure of night diving when most dives occurred.

In addition to accounting for grouped dives among individuals, we controlled for potential spatial autocorrelation among the bins. When one area's dives are correlated with those of the next area, beyond that accounted for by environmental variables, spurious relationships can arise (Crawley 2002). To account for this potential problem, we estimated the average distance of each bin's dives from the point of origin and incorporated this covariate as a random-effects slope within the random term of the models (e.g. 'distancelindividual' in the format required for lmer objects in R) (Crawley 2002).

Our model-building strategy used the all-subsets fixed-term combinations and their interactions to test the specific hypotheses related to the influence of depth, gradient, and time from midnight on the proportion of deep diving per bin. We used the dimension-consistent Bayesian information criterion (BIC), an approximation of the Bayes factor given no informative prior information on relative model support (Burnham \& Anderson 2002), to assign relative strengths of evidence to the different models. This index of model parsimony identifies the relative evidence of model(s) from a set of candidate models. The relative likelihoods of candidate models were calculated using BIC weights (Burnham \& Anderson 2002), with the weight (wBIC) of each model varying from 0 (no support) to 1 (complete support), relative to the entire model set. We adopted BIC weighting as appropriate for determining the contribution of the most important major correlates because the Kullback-Leibler prior, which is used to justify Akaike's information criterion (AIC) weighting, can favour more complex models when sample sizes are large (Burnham \& Anderson 2004, Link \& Barker 2006), as was the case for our dataset.

\section{RESULTS}

\section{Spatial and temporal distribution of dive types}

Deep dives averaged $48.6 \mathrm{~m}$ across all females $($ mean $\pm \mathrm{SD}$ maximum depth $=124.1 \pm 30.2$; see Supplement 1 at www.int-res.com/articles/suppl/m409 p255_supp.pdf), and were broadly focused over the southern shelf and slope margins of the Kerguelen Plateau to the northeast of Heard Island, with concentrations of effort over Gunnari Ridge and the southwestern margins of Shelf Bank (Fig. 2a,b). In some places there was an apparent correspondence between concentrations of deep dives and localised bathymetric features such as small seamounts. This was most apparent around the high diving densities just west and southwest of Shelf Bank. Deep dives occurred most frequently at night between 21:00 and 05:00 h (local time), being most numerous around dusk and dawn (Figs. 1 \& 3).

Shallow dives averaged $8.6 \mathrm{~m}$ (mean $\pm \mathrm{SD}$ maximum depth $=30.0 \pm 3.8$; Supplement 1), and occurred over a more restricted spatial range compared to deep dives, with a clear focus near slope waters along the southern margins of the Kerguelen Plateau northeast of Heard Island (Fig. 2b). There was a concentration over Gunnari Ridge and the southwestern margins of Shell Bank, with a greater focus on slope waters in these regions compared to deep dives. Shallow dives principally occurred at night and were concentrated between 23:00 and 03:00 h (Fig. 3).

The generalised linear mixed-effects models revealed moderate effects of time bin (time from midnight) and bathymetric depth on the proportion of deep dives per bin (Table 1a). The relationships improved notably when only night dives were analysed (removing $16 \%$ of the bins) (Table $1 \mathrm{~b}$ ). The relative support for hour bin and depth was maintained ( $\Sigma$ wBIC $=0.921$ for the 2 top-ranked models; Table $1 \mathrm{~b}$ ), but the $\%$ DE climbed to $28 \%$, suggesting a stronger relationship at night. Most of the variance in proportion of deep dives occurring at night was explained by time bin, with only a small component explained by depth (Table 1b). Supported model coefficients were positive for the effects of depth and time bin on proportion of deep dives (i.e. increasing depth and time from midnight results in a higher proportion of deep dives). 

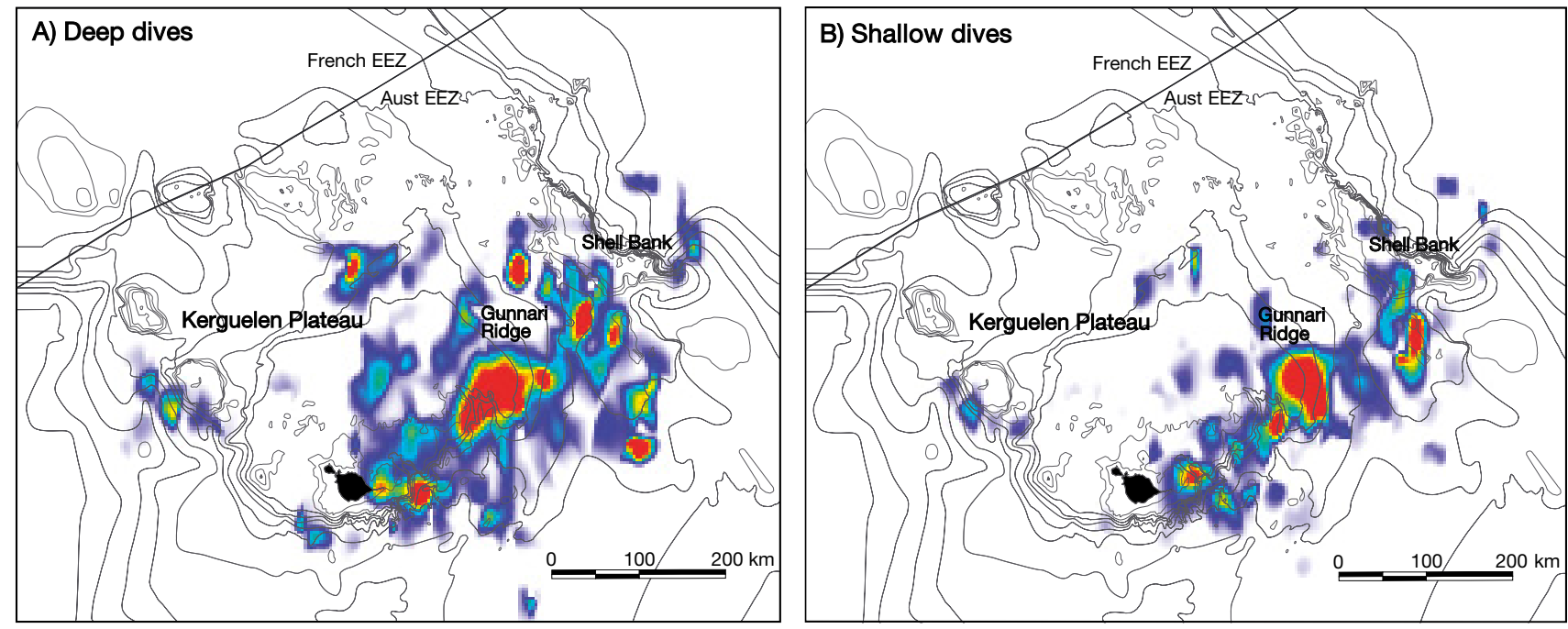

Fig. 2. Arctocepahlus gazella. Spatial distribution of (A) deep and (B) shallow dives in the vicinity of Heard Island. Red and orange tones indicate a high density of dives, while blue tones represent a low density of dives

\section{Behavioural dive groups}

SIMPROF analysis of the dive records of 32 females identified 3 statistically distinct behavioural dive assemblages (groups) (ANOSIM; $\mathrm{p}<0.05)$. Mean dive parameters for the 3 dive groups are detailed in Supplement 1 . These broadly conform to 3 of the 4 behav-

Table 1. The 5 most parsimonious binomial generalized linear mixedeffects models (logit link function) investigating the influence of time (time bins [TB] from midnight - all bins [n $=619]$ considered), or only night dives (time bins 1 to 4 [n $=461]$ ) and bathymetry (average depth [DP] and gradient [GR]) on the proportion of deep dives (PDD) for 22 female Antarctic fur seals. Models include individual (seal) random intercepts to account for within-individual correlation and geographic distance from origin random slopes to account for spatial autocorrelation. Models were ranked according to the Bayesian information criterion (BIC). Also shown are number of parameters (k), maximum log-likelihood (LL), difference in BIC for each model from the most parsimonious model $(\triangle \mathrm{BIC})$, model weight (wBIC), and the percent deviance explained (\%DE) in the response variable (probability of deep diving) by the model under consideration

\begin{tabular}{|lcccrr|}
\hline Model & $\mathrm{k}$ & $\mathrm{LL}$ & \multicolumn{1}{c}{$\Delta \mathrm{BIC}$} & wBIC & $\% \mathrm{DE}$ \\
\hline All time bins (1-6) & & & & & \\
PDD TB + DP & 6 & -89.073 & 0.000 & 0.658 & 10.0 \\
PDD TB & 5 & -93.823 & 3.070 & 0.142 & 5.2 \\
PDD TP + DP + TB × DP & 7 & -88.097 & 4.476 & 0.070 & 11.0 \\
PDD DP & 5 & -94.557 & 4.539 & 0.068 & 4.5 \\
PDD TB + DP + GR & 7 & -89.073 & 6.428 & 0.026 & 10.0 \\
Night bins only (1-4) & & & & & \\
PDD TB & 5 & -51.284 & 0.000 & 0.886 & 28.2 \\
PDD TB + DP & 6 & -50.995 & 5.555 & 0.055 & 28.6 \\
PDD TB + GR & 6 & -51.162 & 5.888 & 0.047 & 28.4 \\
PDD TB + DP + TB $\times$ DP & 7 & -50.306 & 10.311 & 0.005 & 29.6 \\
PDD TB + GR + TB $\times$ GR & 7 & -50.751 & 11.200 & 0.003 & 28.9 \\
\hline
\end{tabular}

ioural dive groups described for lactating Antarctic fur seals at Iles Kerguelen (Lea et al. 2002a): deep ( $n=13)$, shallow/active $(n=13)$ and shallow $(n=6)$, and as such, were adopted here. DFA of the dive parameters indicated a difference between the 3 dive groups (Wilks' lambda $=0.099, F_{4,56}=30.455, \mathrm{p}<0.001$ ), and correctly assigned $91 \%$ of females (29 of 32 cases) using 2 of the behavioural parameters (vertical depth travelled per day and night-dive frequency; jackknifed classification matrix: $92 \%$ [12 of 13] correctly assigned to the deep dive group, $85 \%$ [11 of 13] correctly assigned to shallow/active dive group, and $100 \%$ [6 of 6] correctly assigned to the shallow dive group). The canonical scores that distinguished the behavioural dive groups are plotted in Fig. 4. The addition of maximum distance and heading for the subset of 22 females (instrumented with PTTs and TDRs) produced a similar DFA result that included 3 behavioural parameters (vertical depth travelled per day, night-dive frequency, and heading) with similar power to detect differences among the 3 groups (Wilks' lambda = 0.047, $F_{6,34}=20.397, \mathrm{p}<0.001$; jackknifed classification matrix: overall classification success was $91 \%$ [17 of 22] correctly assigned, $89 \%$ [8 of 9] correctly assigned to the deep group, $89 \%$ [8 of 9] correctly assigned to shallow/active group, and $100 \%$ [4 of 4] correctly assigned to shallow group). The morphology of the seals (standard length [cm] and mass [kg]) did not vary as a function of behavioural dive group (ANOVA; length 


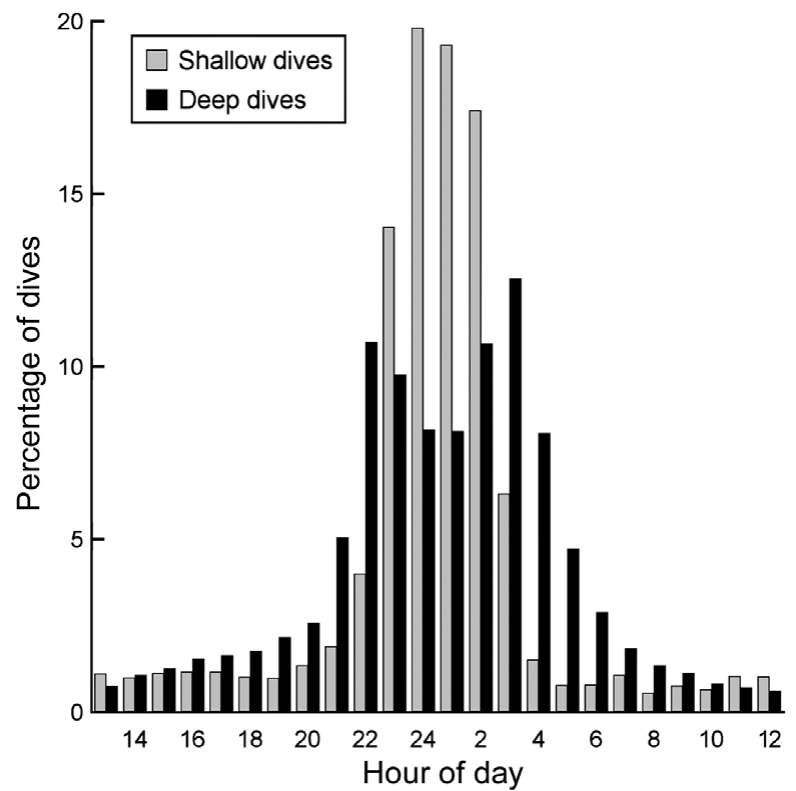

Fig. 3. Arctocepahlus gazella. Temporal distribution of deep and shallow dives among 32 lactating Antarctic fur seal

females fitted with time-depth recorders at Heard Island

$F_{2,29}=0.291, \mathrm{p}=0.749 ;$ mass $\left.F_{2,29}=1.715, \mathrm{p}=0.1977\right)$ (Supplement 1).

Females in the deep dive group dived broadly over the shelf waters of the Kerguelen Plateau as well as the slope and oceanic waters to the northeast, east and northwest of Heard Island (Fig. 5a). Individuals in the shallow/active dive group focused their diving effort along the shelf and slope margins to the northeast of Heard Island, with concentrations over Gunnari Ridge

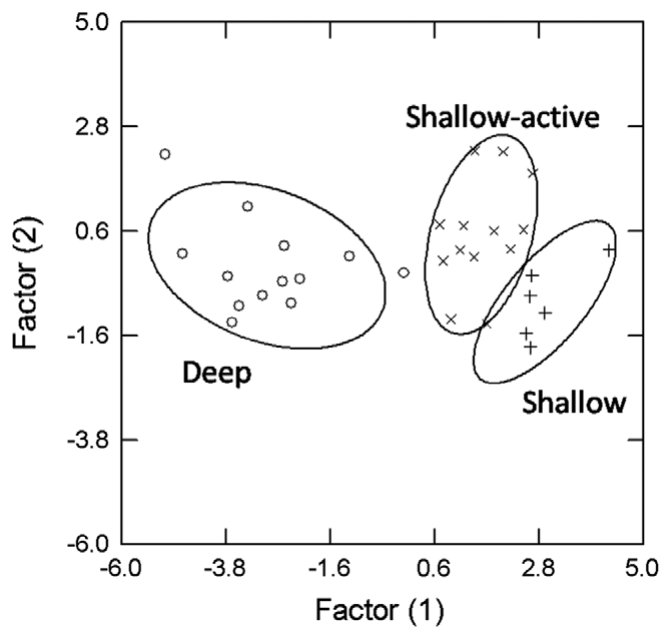

Fig. 4. Arctocepahlus gazella. Canonical scores plot for the 32 lactating Antarctic fur seals fitted with time-depth recorders indicating the separation among the 3 main behavioural dive groups (deep, shallow-active, and shallow). Canonical discriminant functions were based on 2 diving behaviour parameters: night dive frequency (number of dives $\mathrm{h}^{-1}$ of night) and vertical depth travelled $\left(\mathrm{d}^{-1}\right)$
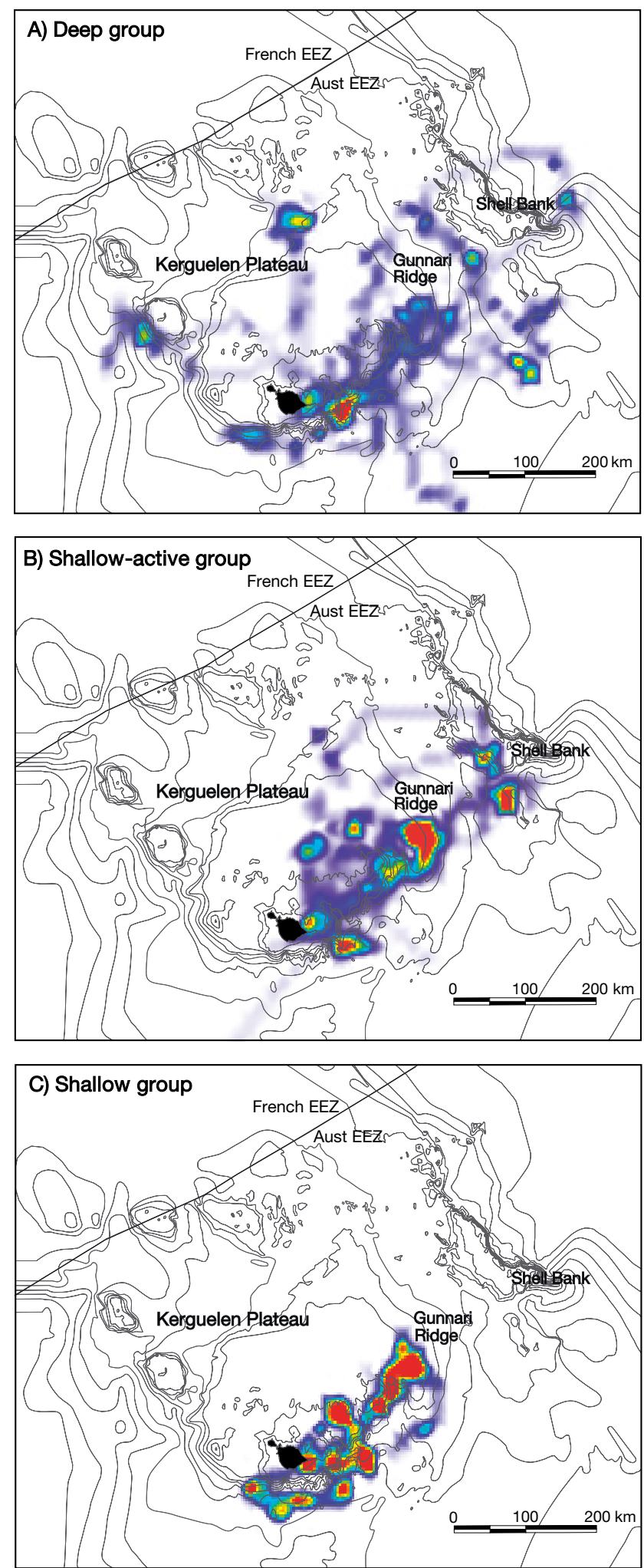

Fig. 5. Arctocepahlus gazella. Spatial distribution of the three main behavioural dive groups: (A) deep, (B) shallow-active, and $(C)$ shallow, in the vicinity of Heard Island. Red and orange tones indicate a high density of dives, while blue tones represent a low density of dives 
and along the southwestern margin of Shell Bank (Fig. 5b). Individuals in the shallow dive group focused their diving effort over the southern margins of the Kerguelen Plateau with a concentration in the slope waters to the immediate south and northeast of Heard Island (Fig. 5c). There was also a concentration of dive effort over Gunnari Ridge (Fig. 5c).

\section{DISCUSSION}

The diet and foraging behaviour of Antarctic fur seals has been well described for all major populations across their range. At the western (Scotia Arc, Antarctic Peninsula, and southern Indian Ocean) and eastern (Macquarie Island) extremes of the range, lactating Antarctic fur seals principally target Antarctic krill Euphausia superba and myctophid fishes, respectively; while populations in the central part of the range (near the Antarctic Polar Front in the southern Indian Ocean) target a mixture of meso- and bentho-pelagic prey such as myctophid, nototheniid, and channichthyid fishes and squid (Green et al. 1989, Reid 1995, Reid \& Arnould 1996, Cherel et al. 1997, Goldsworthy et al. 1997, Lea et al. 2002b, Robinson et al. 2002). Fur seals at Heard Island, like at Iles Kerguelen and Macquarie Island (Cherel et al. 1997, Goldsworthy et al. 1997, Lea et al. 2002b, Robinson et al. 2002, Lea et al. 2008), also eat a high proportion of myctophids (Green et al. 1989, 1997, Finger 2003, Casper et al. 2007). However, channichthyid fishes are more important in the diet of fur seals at Heard Island in contrast to Iles Kerguelen and Macquarie Island. Based on faecal samples collected from female Antarctic fur seals at Heard Island during the time period of the present study, channichthyid fish dominated (84.5\% prey biomass), especially mackerel icefish Champsocephalus gunnari $(80.2 \%$ prey biomass), with myctophids forming the other major fish prey (15.4\% prey biomass) (Table 2 ).

Regional differences in diet and prey availability are thought to drive variability in the diving behaviour observed across the range of Antarctic fur seals (Boyd \& Croxall 1992, Boyd et al. 1994, Goebel et al. 2000, Guinet et al. 2001, Staniland \& Boyd 2003, Staniland et al. 2004, Baileul et al. 2005, Lea et al. 2008, Biuw et al. 2009). The icefish/myctophid diet at Heard Island may therefore account for the bouts of near-surface (shallow) and deeper (deep) dives described in the present study, the extent of which have not been reported for other populations. Spatial and temporal differences in the distribution of these distinctive dive types (deep and shallow) support this hypothesis. Deep dives that predominated around dusk and dawn (mean depth $48.6 \mathrm{~m}$, range 25.6 to $64.6 \mathrm{~m}$; mean maximum depth $124.1 \mathrm{~m}$, range 78.0 to $206.0 \mathrm{~m}$ ) are consistent with
Table 2. Prey of female Antarctic fur seals at Heard Island based on 39 faecal samples collected between December and February 2000-2001. The number of otoliths recovered for each fish family (n), the frequency by number (FBN\%), and estimated biomass (\%) are presented. Data from Finger (2003)

\begin{tabular}{|lcc|}
\hline Prey taxa & FBN\% & Biomass \\
\hline Myctophidae (n = 265) & 65.0 & 15.4 \\
Protomyctophum choriodon & 15.7 & 1.1 \\
P. bolini & 1.5 & 0.0 \\
Electrona antarctica & 3.9 & 0.1 \\
E. subaspera & 0.2 & 0.2 \\
Gymnoscopelus fraseri & 5.4 & 0.6 \\
G. nicholsi & 23.0 & 13.3 \\
Krefftichthys anderssoni & 15.2 & 0.1 \\
Channichthyidae (n = 142) & 34.8 & 84.5 \\
Champsocephalus gunnari & 33.3 & 80.2 \\
Channichthys rhinoceratus & 1.5 & 4.3 \\
Gempylidae (n = 1) & 0.2 & 0.1 \\
Paradiplospinus gracilis & 0.2 & 0.1 \\
\hline
\end{tabular}

seals targeting mackerel icefish (Fig. 2a). Mackerel icefish are semi-pelagic and are common to shelf waters around the subantarctic island groups of the Scotia Arc, Bouvet Island, and Kerguelen Plateau (Kock \& Everson 1997). They are typically found on or close to the sea bed during the day, but undertake diurnal feeding migrations up into the water column (Frolkina \& Shlibanov 1991, Frolkina \& Kasatkina 2001) where they are most commonly found between 150 and $250 \mathrm{~m}$ (i.e. continental shelf waters) (Everson et al. 1999). On the Kerguelen Plateau, they feed mainly on amphipods, euphausiids, and other zooplankton (Duhamel \& Pletikosic 1983, Duhamel et al. 1991, Kock \& Everson 1997). In contrast, the shallow dives (mean depth $8.6 \mathrm{~m}$, range 5.1 to $13.5 \mathrm{~m}$; mean maximum depth $30.0 \mathrm{~m}$, range 15.0 to $39.0 \mathrm{~m}$ ), which were concentrated around midnight, most likely reflect seals targeting myctophid fish (Fig. 2b). This dive pattern, along with their spatial concentration along the shelf margins northeast of Heard Island (Fig.2b), is consistent with fur seals exploiting myctophid fishes that migrate into near-surface waters (top $50 \mathrm{~m}$ ) at night (Duhamel 1998, Duhamel et al. 2000, Guinet et al. 2001). Furthermore, the depth range and density of these shallow dives are similar to those reported for fur seals at Macquarie Island where the diet is almost entirely myctophid fish (principally Electrona subaspera) (Goldsworthy et al. 1997, Robinson et al. 2002) and average dive depths (9 to $15 \mathrm{~m}$ ) are among the shallowest reported among Antarctic fur seals (Goldsworthy et al. 1997, Robinson et al. 2002).

Staniland et al. $(2004,2007)$ identified that differences in diving behaviour and diet were associated with geographic differences (depth and distance) in 
the location of foraging. The daily switches between bouts of deep and shallow diving suggests that fur seals can also adjust their diving behaviour in response to temporal changes in the availability of prey. Our observations suggest that such prey (dive type) switching can occur rapidly and in the same geographic location, but that location also accounts for an important component of the variation in diving behaviour. We found that the extent to which shallow and deep dives were performed was weakly related to the underlying water depth where seals foraged, and this was most likely due to the relative distributions of their principal prey. Deep dives were associated with deep shelf habitats on the Kerguelen Plateau, with a concentration around Gunnari Ridge (Fig. 2a). Shallow dives were focused in similar regions, but were most concentrated along the southern slope margins of the Kerguelen Plateau (Fig. 2b). Given that some myctophid species appear to aggregate in near-surface waters in the middle of the night (as at Macquarie Island), we interpret our results as evidence that fur seals are targeting mackerel icefish when available but switch to myctophids in the middle of the night when they might be more efficiently captured (i.e. aggregated in nearsurface schools). Myctophid fish are more energetically profitable than mackerel icefish (Lea et al. 2002b, Tierney et al. 2002), so it is reasonable to assume that seals target myctophids to maximise calorific intake by foraging on these smaller prey species when it is most profitable.

Given that fur seal populations at Iles Kerguelen and Heard Island are only about $450 \mathrm{~km}$ apart, and they occur on the same submarine plateau just north and south of the Polar Frontal Zone (PFZ), it is relevant to speculate how these geographic differences might influence their respective foraging strategies. The behavioural dive groups of lactating Antarctic fur seals at Heard Island broadly conform to those described at Iles Kerguelen (Lea et al. 2002a). At Heard Island, deep divers had deeper mean dive depths $(31.4 \mathrm{~m})$ compared to individuals in the other 2 dive groups (26.9 shallow-active group and $26.0 \mathrm{~m}$ shallow group; Supplement 1). The 2 shallow groups were principally distinguished from each other by differences in activity, with shallow-active divers having elevated overall and night-dive frequencies (12.7 and 33.4 dives per hour, respectively) compared to the shallow group (9.8 and 21.2 dives per hour, respectively). Similar results were found at Iles Kerguelen (Lea et al. 2002a). At Heard Island, deep divers allocated less time at night diving to shallow depths $(17.6 \%)$ compared to the 2 shallow dive groups (45.6 and $35.3 \%$, respectively; Supplement 1).

There were 2 important differences between the foraging behaviour of lactating Antarctic fur seals at
Heard Island and Iles Kerguelen: (1) the daytime dive group was absent at Heard Island, and (2) mean dive depths were much deeper at Iles Kerguelen (53 m) compared to Heard Island $(29 \mathrm{~m})$. Only 3 of the 117 sampled seals occupied the daytime dive group at Iles Kerguelen (Lea et al. 2002a), so it is possible that the absence of this behavioural group at Heard Island was due to undersampling. Some daytime dives were recorded at Heard Island, but these accounted for just $17 \%$ of all dives, and all females focused their dive effort between dusk and dawn (>80\% of all dives). Differences in the mean depth of dives between Iles Kerguelen and Heard Island might be attributable to foraging habitat differences. Lactating females at Iles Kerguelen focus their foraging effort in deep oceanic waters to the northeast of the archipelago in the region of the PFZ. This is a region of high myctophid abundance due to its mesoplankton productivity (Koslov et al. 1991). The proximity of the PFZ provides fur seals from Iles Kerguelen with a reliable region of available prey and consequent savings in the amount of time and energy expended commuting between foraging areas and colonies. A recent study undertaken on Antarctic fur seals in the western part of the Iles Kerguelen at Iles Nuageuses has shown that seals from this population forage west of the archipelago in waters not associated with the PFZ (Lea et al. 2008). PFZ waters are unlikely to be accessible to lactating fur seals at Heard Island that instead appear to focus their foraging effort in shallower shelf and slope waters on the southern margin of the Kerguelen Plateau. These marked differences in foraging habitat could account for the differences in dive depth, behaviour, and diet of the 2 populations. The depth criterion for a dive to be included in analyses was greater in Lea et al.'s (2002a) study ( $\geq 4 \mathrm{~m}$ compared to $\geq 2.5 \mathrm{~m}$ in the present study), so inter-population differences in dives could also be attributable to subtle differences in methods. Reid et al. (2006) examined the variation of fish in the diet of Antarctic fur seals in the Atlantic sector of the Southern Ocean and found a strong relationship between the fish prey targeted and the marine habitat at each site. Pelagic species such as myctophids were targeted from colonies where the distance to the shelf break was short. Benthopelagic species such as nototheniids and channichthyids were more common at sites surrounded by extensive continental shelves.

We also found evidence for spatial differences in the distribution of foraging effort of females within each of the 3 behavioural dive groups (Fig. 5). Females within the deep behavioural group (characterised by high vertical depth travelled per day, high night-dive frequency, and a low proportion of shallow dives), were the most wide-ranging group, covering areas of the Kerguelen Plateau not visited by the other groups 
(Supplement 1, Fig. 5). In contrast, the distribution of foraging effort of females within the shallow-active and shallow groups (characterised by a higher proportion of shallow dives) were more concentrated around the slope margins of the Kerguelen Plateau to the northeast of Heard Island (Supplement 1, Fig. 5b,c). This concentration was most notable for females in the shallow group (Fig. 5c). The low vertical depth travelled per day and high proportion of shallow dives suggest that females within the shallow behaviour dive group principally target myctophids, which is supported by the concentration of their foraging effort along the shelf margin where the density of myctophids is greatest (Duhamel 1998, Duhamel et al. 2000, Guinet et al. 2001). In contrast, the high vertical depth travelled per day and high frequency of deep dives of females within the deep behaviour dive group suggest they principally target channichthyid fish, which is also supported by the concentration of foraging effort more broadly over the shelf waters where channichthyid density is expected to be greatest (Kock \& Everson 2003). Based on these observations, and the more intermediate diving behaviour and distribution of foraging effort of females within the shallow-active group, we suggest that females within this group have a more mixed myctophid/channichthyid diet compared to females within the deep and shallow behavioural dive group. These dietary predictions based upon the spatial distribution of foraging effort, diving behaviour, and dive types could be tested following a similar approach to Staniland et al. (2007).

\section{CONCLUSIONS}

We have identified 2 main dive types used by Antarctic fur seal females at Heard Island that likely reflect the targeting of their 2 principal prey, channicthyid and myctophid fish. None of the fur seals we monitored used deep or shallow dives exclusively. Instead, seals used both dive types depending on where and when they foraged to match the behaviour of available prey. Importantly, we provide evidence that the diving strategies of seals are not only influenced by where foraging takes pace, but when. Foraging experience and the metabolic capabilities of individuals are also likely to be important determinants of the extent to which different foraging strategies are employed (Lea et al. 2002a, Staniland et al. 2007), although we found no evidence that diving behaviour was related to female morphology. Comparisons between the diet and foraging strategies of lactating Antarctic fur seals at the northern and southern parts of the Kerguelen Plateau suggest that in contrast to populations at Iles Kerguelen, which target high densi- ties of myctophids associated with the nearby PFZ, fur seals at Heard Island adopt a mixed-prey and dynamic foraging strategy focused along the shelf/slope margins, optimising access to both channicthyid and myctophid fish.

Acknowledgements. We thank the La Trobe University Animal Ethics Committee and the Department of the Environment and Heritage (Australia) for approval and permits to undertake this research. Logistic and financial support was provided by the Australian Antarctic Division and the Australian Antarctic Science Advisory Committee. We thank P. Scott for assistance in the field, and S. McClatchie and P. Burch for analytical support.

\section{LITERATURE CITED}

Antonelis GA, Sinclair EH, Ream RR, Robson BW (1997) Interisland variation in the diet of female northern fur seals (Callorhinus ursinus) in the Bering Sea. J Zool 242: 435-451

Austin D, Bowen WD, McMillan JI, Iverson SJ (2006) Linking movement, diving, and habitat to foraging success in a large marine predator. Ecology 87:3095-3108

Bailleul F, Luque S, Dubroca L, Arnould JPY, Guinet C (2005) Differences in foraging strategy and maternal behaviour between two sympatric fur seal species at the Crozet Islands. Mar Ecol Prog Ser 293:273-282

> Baylis AMM, Page B, Goldsworthy SD (2008) Colony-specific foraging areas of lactating New Zealand fur seals. Mar Ecol Prog Ser 361:279-290

Beauplet G, Dubroca L, Guinet C, Cherel Y, Dabin W, Gagne C, Hindell M (2004) Foraging ecology of subantarctic fur seals Arctocephalus tropicalis breeding on Amsterdam Island: seasonal changes in relation to maternal characteristics and pup growth. Mar Ecol Prog Ser 273:211-225

Benoit-Bird KJ, Au WWL (2003) Prey dynamics affect foraging by a pelagic predator (Stenella longirostris) over a range of spatial and temporal scales. Behav Ecol Sociobiol 53:364-373

Biuw B, Krafft BA, Hofmeyr GJG, Lyderson C, Kovacs KM (2009) Time budgets and at-sea behaviour of lactating female Antarctic fur seals Arctocephalus gazella at Bouvetøya. Mar Ecol Prog Ser 385:271-284

> Blackburn TM, Duncan RP (2001) Establishment patterns of exotic birds are constrained by non-random patterns in introduction. J Biogeogr 28:927-939

Bonadonna F, Lea MA, Dehorter O, Guinet C (2001) Foraging ground fidelity and route-choice tactics of a marine predator: the Antarctic fur seal Arctocephalus gazella. Mar Ecol Prog Ser 223:287-297

> Boyd IL (1996) Temporal scales of foraging in a marine predator. Ecology 77:426-434

> Boyd IL, Croxall JP (1992) Diving behaviour of lactating Antarctic fur seals. Can J Zool 70:919-928

$>$ Boyd IL, Arnould JPY, Barton T, Croxall JP (1994) Foraging behaviour of Antarctic fur seals during periods of contrasting prey abundance. J Anim Ecol 63:703-713

Boyd IL, McCafferty DJ, Reid K, Taylor R, Walker TR (1998) Dispersal of male and female Antarctic fur seals (Arctocephalus gazella). Can J Fish Aquat Sci 55:845-852

Boyd IL, Staniland IJ, Martin AR (2002) Distribution of foraging by female Antarctic fur seals. Mar Ecol Prog Ser 242: 285-294 
Bradshaw CJA, Hindell MA, Sumner MD, Michael KJ (2004) Loyalty pays: potential life history consequences of fidelity to marine foraging regions by southern elephant seals. Anim Behav 68:1349-1360

Brook BW, Traill LW, Bradshaw CJA (2006) Minimum viable population sizes and global extinction risk are unrelated. Ecol Lett 9:375-382

Burnham KP, Anderson DR (2002) Model selection and multimodal inference: a practical information-theoretic approach. Springer-Verlag, New York

Burnham KP, Anderson DR (2004) Multimodel inferenceunderstanding AIC and BIC in model selection. Sociol Methods Res 33:261-304

- Casper RM, Jarman SN, Gales NJ, Hindell MA (2007) Combining DNA and morphological analyses of faecal samples improves insight into trophic interactions: a case study using a generalist predator. Mar Biol 152:815-825

Cherel Y, Guinet C, Tremblay Y (1997) Fish prey of Antarctic fur seals Arctocephalus gazella at Ile de Croy, Kerguelen. Polar Biol 17:87-90

Clarke KR, Warwick RM (2005) PRIMER-6. Natural Environment Research Council, Plymouth

Crawley MJ (2002) Statistical computing. An introduction to data analysis using S-Plus. John Wiley, Chichester

Duhamel G (1998) The pelagic fish community of the Polar Frontal Zone off the Kerguelen Islands. In: Di Prisco G, Pisano E, Clarke A (eds) Fishes of Antarctica: a biological overview. Springer, Heidelberg, p 63-74

Duhamel G, Pletikosic M (1983) Données biologiques sur les Nototheniidae des îles Crozet. Cybium 7:43-57

Duhamel G, di Prisco G, Maresca B, Tota B (1991) The biological and demographic peculiarities of the icefish Champsocephalus gunnari Lonnberg, 1905 from the Kerguelen Plateau. In: Di Prisco G, Maresca B, Tota B (eds) Biology of Antarctic fishes. Springer-Verlag, Berlin, p 40-53

Duhamel G, Koubbi P, Ravier C (2000) Day and night mesopelagic fish assemblages off the Kerguelen Islands (Southern Ocean). Polar Biol 23:106-112

Everson I, Parkes G, Kock KH, Boyd IL (1999) Variation in standing stock of mackerel icefish Champsocephalus gunnari at South Georgia. J Appl Ecol 36:591-603

Finger A (2003) Diet of Antarctic fur seals (Arctocephalus gazella) at Heard Island. Honours dissertation, La Trobe University

Frolkina ZA, Kasatkina SM (2001) Possible causes of variation of Champsocephalus gunnari vertical and horizontal distribution. WAMI-01/8. CCAMLR (mimeogr.), Hobart, p 3-14

Frolkina ZA, Shlibanov VI (1991) Vertical migrations of mackerel icefish (Champsocephalus gunnari) on the south Georgia shelf. Selected Scientific Papers (SC-CAMLR SSP/8). CCAMLR, Hobart, p 3-14

Gentry RL, Costa DP, Croxal JP, David JHM and others (1986a) Synthesis and conclusions. In: Gentry RL, Kooyman GL (eds) Fur seals: maternal strategies on land and at sea. Princeton University Press, Princeton, p 220-264

Gentry RL, Kooyman GL, Goebel ME (1986b) Feeding and diving behaviour of northern fur seals. In: Gentry RL, Kooyman GL (eds) Fur seals: maternal strategies on land and at sea. Princeton University Press, Princeton, p 61-78

Goebel ME, Bengtson JL, Delong RL, Gentry RL, Loughlin TR (1991) Diving patterns and foraging locations of female northern fur seals. Fish Bull 89:171-179

Goebel ME, Costa DP, Crocker DE, Sterling JT, Demer DA (2000) Foraging ranges and dive patterns in relation to bathymetry and time-of-day of Antarctic fur seals, Cape Sherriff, Livingston Island, Antarctica. In: Davidson W,
Howard-Williams C, Broady P (eds) Antarctic ecosystems: models for wider ecological understanding. Caxton Press, Christchurch, p 47-50

Goldsworthy SD, Hindell MA, Crowley HM (1997) Diet and diving behaviour of sympatric fur seals Arctocephalus gazella and A. tropicalis at Macquarie Island. In: Hindell MA, Kemper C (eds) Marine mammal research in the southern hemisphere, Vol 1. Status, ecology and medicine. Surrey Beatty and Sons, Chipping Norton, p 151-163

Green K, Burton HR, Williams R (1989) The diet of Antarctic fur seals Arctocephalus gazella during the breeding season at Heard Island. Antarct Sci 1:317-324

Green K, Williams R, Burton H (1997) Foraging ecology of Antarctic fur seals Arctocephalus gazella around Heard Island. In: Hindell MA, Kemper C (eds) Marine mammal research in the southern hemisphere, Vol 1. Status, ecology and medicine. Surrey Beatty and Sons, Chipping Norton, p 105-113

Guinet C, Dubroca L, Lea MA, Goldsworthy S and others (2001) Spatial distribution of foraging in female Antarctic fur seals Arctocephalus gazella in relation to oceanographic variables: a scale-dependent approach using geographic information systems. Mar Ecol Prog Ser 219: 251-264

Harcourt RG, Bradshaw CJA, Davis LS (2001) Summer foraging behaviour of a generalist predator, the New Zealand fur seal (Arctocephalus forsteri). Wildl Res 28:599-606

> Hooker SK, Baird RW (2001) Diving and ranging behaviour of odontocetes: a methodological review and critique. Mammal Rev 31:81-105

Kock KH, Everson I (1997) Biology and ecology of mackerel icefish, Champsocephalus gunnari: an Antarctic fish lacking hemoglobin. Comp Biochem Physiol A 118:1067-1077

Kock KH, Everson I (2003) Shedding new light on the life cycle of mackerel icefish in the Southern Ocean. J Fish Biol 63:1-21

Kozlov AN, Shust KV, Zemsky AV (1991) Seasonal and interannual variability in the distribution of Electrona carlsbergi in the southern polar front area (the area north of south Georgia is used as an example). Selected Scientific Papers (SC-CAMLR-SSP/7), CCAMLR, Hobart

Le Boeuf BJ, Crocker DE, Costa DP, Blackwell SB, Webb PM, Houser DS (2000) Foraging ecology of northern elephant seals. Ecol Monogr 70:353-382

Lea MA, Hindell M, Guinet C, Goldsworthy S (2002a) Variability in the diving activity of Antarctic fur seals, Arctocephalus gazella, at Iles Kerguelen. Polar Biol 25:269-279

Lea MA, Nichols PD, Wilson G (2002b) Fatty acid composition of lipid-rich myctophids and mackerel icefish (Champsocephalus gunnari)-Southern Ocean food-web implications. Polar Biol 25:843-854

> Lea MA, Guinet C, Cherel Y, Hindell M, Dubroca L, Thalmann S (2008) Colony-based foraging segregation by Antarctic fur seals at the Kerguelen Archipelago. Mar Ecol Prog Ser 358:273-287

> Link WA, Barker RJ (2006) Model weights and the foundations of multimodel inference. Ecology 87:2626-2635

Macdonald DW, Rushton S (2003) Modelling space use and dispersal of mammals in real landscapes: a tool for conservation. J Biogeogr 30:607-620

> McConnell BJ, Chambers C, Fedak MA (1992) Foraging ecology of southern elephant seals in relation to the bathymetry and productivity of the Southern Ocean. Antarct Sci 4:393-398

Page B, McKenzie J, Goldsworthy SD (2005) Inter-sexual differences in New Zealand fur seal diving behaviour. Mar Ecol Prog Ser 304:249-264 
Page B, McKenzie J, Sumner MD, Coyne M, Goldsworthy SD (2006) Spatial separation of foraging habitats among New Zealand fur seals. Mar Ecol Prog Ser 323:263-279

R Development Core Team (2009) R: a language and environment for statistical computing. R Foundation for Statistical Computing, Vienna

Reid K (1995) The diet of Antarctic fur seals (Arctocephalus gazella Peters 1875) during winter at South Georgia. Antarct Sci 7:241-249

Reid K, Arnould JPA (1996) The diet of Antarctic fur seals Arctocephalus gazella during the breeding season at South Georgia. Polar Biol 16:105-114

Reid K, Davis D, Staniland IJ (2006) Spatial and temporal variability in the fish diet of Antarctic fur seal (Arctocephalus gazella) in the Atlantic sector of the Southern Ocean. Can J Zool 84:1025-1037

Robinson SA, Goldsworthy SD, van den Hoff J, Hindell MA (2002) The foraging ecology of two sympatric fur seal species, Arctocephalus gazella and Arctocephalus tropicalis, at Macquarie Island during the austral summer. Mar Freshw Res 53:1071-1082

Robinson PW, Tremblay Y, Crocker DE, Kappes MA and others (2007) A comparison of indirect measures of feeding behaviour based on ARGOS tracking data. Deep-Sea Res II 54:356-368

Robson BR, Goebel ME, Baker JD, Ream RR and others (2004) Separation of foraging habitat among breeding sites of a

Editorial responsibility: Yves Cherel,

Villiers-en-Bois, France colonial marine predator, the northern fur seal (Callorhinus ursinus). Can J Zool 82:20-29

Sinclair EH, Loughlin TR, Pearcy W (1994) Prey selection by northern fur seals (Callorhinus ursinus) in the eastern Bering Sea. Fish Bull 92:144-156

Staniland IJ, Boyd IL (2003) Variation in the foraging location of Antarctic fur seals (Arctocephalus gazella) and the effects on diving behavior. Mar Mamm Sci 19:331-343

Staniland IJ, Reid K, Boyd IL (2004) Comparing individual and spatial influences on foraging behaviour in Antarctic fur seals Arctocephalus gazella. Mar Ecol Prog Ser 275: $263-274$

Staniland IJ, Boyd IL, Reid K (2007) An energy-distance trade-off in a central-place forager, the Antarctic fur seal (Arctocephalus gazella). Mar Biol 152:233-241

Sterling JT, Ream RR (2004) At-sea behavior of juvenile male northern fur seals (Callorhinus ursinus). Can J Zool 82: 1621-1637

Tierney M, Hindell M, Goldsworthy SD (2002) Energy content of mesopelagic fish from Macquarie Island. Antarct Sci 14:225-230

Weimerskirch H, Wilson RP, Lys P (1997) Activity pattern of foraging in the wandering albatross: a marine predator with two modes of prey searching. Mar Ecol Prog Ser 151:245-254

> Zeppelin TK, Ream RR (2006) Foraging habitats based on the diet of female northern fur seals (Callorhinus ursinus) on the Pribilof Islands, Alaska. J Zool 270:565-576

Submitted: December 19, 2008; Accepted: April 8, 2010

Proofs received from author(s): June 1, 2010 